\title{
Mixed Phase Modeling in GlennICE With Application to Engine Icing
}

William B. Wright

ASRC Aerospace Corporation, Cleveland, Ohio

Philip C.E. Jorgenson and Joseph P. Veres

Glenn Research Center, Cleveland, Ohio 


\section{NASA STI Program . . . in Profile}

Since its founding, NASA has been dedicated to the advancement of aeronautics and space science. The NASA Scientific and Technical Information (STI) program plays a key part in helping NASA maintain this important role.

The NASA STI Program operates under the auspices of the Agency Chief Information Officer. It collects, organizes, provides for archiving, and disseminates NASA's STI. The NASA STI program provides access to the NASA Aeronautics and Space Database and its public interface, the NASA Technical Reports Server, thus providing one of the largest collections of aeronautical and space science STI in the world. Results are published in both non-NASA channels and by NASA in the NASA STI Report Series, which includes the following report types:

- TECHNICAL PUBLICATION. Reports of completed research or a major significant phase of research that present the results of NASA programs and include extensive data or theoretical analysis. Includes compilations of significant scientific and technical data and information deemed to be of continuing reference value. NASA counterpart of peer-reviewed formal professional papers but has less stringent limitations on manuscript length and extent of graphic presentations.

- TECHNICAL MEMORANDUM. Scientific and technical findings that are preliminary or of specialized interest, e.g., quick release reports, working papers, and bibliographies that contain minimal annotation. Does not contain extensive analysis.

- CONTRACTOR REPORT. Scientific and technical findings by NASA-sponsored contractors and grantees.
- CONFERENCE PUBLICATION. Collected papers from scientific and technical conferences, symposia, seminars, or other meetings sponsored or cosponsored by NASA.

- SPECIAL PUBLICATION. Scientific, technical, or historical information from NASA programs, projects, and missions, often concerned with subjects having substantial public interest.

- TECHNICAL TRANSLATION. Englishlanguage translations of foreign scientific and technical material pertinent to NASA's mission.

Specialized services also include creating custom thesauri, building customized databases, organizing and publishing research results.

For more information about the NASA STI program, see the following:

- Access the NASA STI program home page at http://www.sti.nasa.gov

- E-mail your question via the Internet to help@ sti.nasa.gov

- Fax your question to the NASA STI Help Desk at $443-757-5803$

- Telephone the NASA STI Help Desk at 443-757-5802

- Write to: NASA Center for AeroSpace Information (CASI) 7115 Standard Drive Hanover, MD 21076-1320 
NASA/TM-2011-216978

AIAA-2010-7674

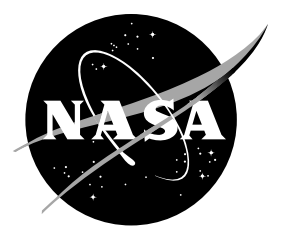

\section{Mixed Phase Modeling in GlennICE With Application to Engine Icing}

William B. Wright

ASRC Aerospace Corporation, Cleveland, Ohio

Philip C.E. Jorgenson and Joseph P. Veres

Glenn Research Center, Cleveland, Ohio

Prepared for the

Atmospheric and Space Environments Conference

sponsored by the American Institute of Aeronautics and Astronautics

Toronto, Ontario, Canada August 2-5, 2010

National Aeronautics and

Space Administration

Glenn Research Center

Cleveland, Ohio 44135 


\section{Acknowledgments}

The authors would like to thank the members of the NASA Glenn Icing Branch for their feedback on this report, in particular Jen-Ching Tsao, Colin Bidwell, Gene Addy, and Mark Potapczuk. William B. Wright would also like to thank NASA for their continued support under contract.

This report is a formal draft or working paper, intended to solicit comments and ideas from a technical peer group.

This report contains preliminary findings, subject to revision as analysis proceeds.

Trade names and trademarks are used in this report for identification only. Their usage does not constitute an official endorsement, either expressed or implied, by the National Aeronautics and Space Administration.

Level of Review: This material has been technically reviewed by technical management.

Available from

NASA Center for Aerospace Information 7115 Standard Drive

Hanover, MD 21076-1320
National Technical Information Service 5301 Shawnee Road Alexandria, VA 22312

Available electronically at http://www.sti.nasa.gov 


\title{
Mixed Phase Modeling in GlennICE With Application to Engine Icing
}

\author{
William B. Wright \\ ASRC Aerospace Corporation \\ Cleveland, Ohio 44135 \\ Philip C.E. Jorgenson and Joseph P. Veres \\ National Aeronautics and Space Administration \\ Glenn Research Center \\ Cleveland, Ohio 44135
}

\begin{abstract}
A capability for modeling ice crystals and mixed phase icing has been added to GlennICE. Modifications have been made to the particle trajectory algorithm and energy balance to model this behavior. This capability has been added as part of a larger effort to model ice crystal ingestion in aircraft engines. Comparisons have been made to four mixed phase ice accretions performed in the Cox icing tunnel in order to calibrate an ice erosion model. A sample ice ingestion case was performed using the Energy Efficient Engine ( $\left.\mathrm{E}^{3}\right)$ model in order to illustrate current capabilities. Engine performance characteristics were supplied using the Numerical Propulsion System Simulation (NPSS) model for this test case.
\end{abstract}

\section{Introduction}

Mason (Ref. 1) describes a situation where an aircraft engine can encounter rollbacks and flameouts at high altitude conditions due to ice crystal ingestion. Numerous in-fight encounters had been observed. It was hypothesized that the cause of the incidents was the ingestion of a high volume of ice crystals into the engine. More so, this report theorized that the ice crystals could be tolerated if the crystals remained small solid particles. However, this paper suggested that the ice crystals first melt upon contact with warm engine parts. Subsequent ice particles are then more likely to stick to the wetted surface, allowing ice accumulation to occur. The engine abnormalities then occur when this ice buildup sheds. Venkataramani (Ref. 2), Veillard (Ref. 3), and Rios (Ref. 4) describe previous attempts to model the engine icing problem. This report will describe an overview of the GlennICE and NPSS software. It will then describe the modifications made to GlennICE in order to model ice crystal scenarios. Included in these modifications is an empirical relationship for ice particle induced mass loss (ice erosion) that used to govern mixed-phase conditions. Data for this relationship was taken from a report by Al-Khalil (Ref. 5). Finally, a sample case was performed for ice crystal ingestion using the results from the NPSS model to provide inputs to GlennICE.

\section{Nomenclature}

$\begin{array}{ll}C_{d} & \text { drag coefficient } \\ C_{p} & \text { heat capacity } \\ D_{a, i} & \text { diffusivity of ice in air } \\ d & \text { particle size } \\ F & \text { force } \\ H & \text { enthalpy } \\ \text { IWC } & \text { ice water content } \\ h & \text { heat transfer coefficient }\end{array}$




$\begin{array}{ll}k & \text { thermal conductivity } \\ L & \text { characteristic length } \\ L_{\text {sub }} & \text { heat of sublimation } \\ \mathrm{LWC} & \text { liquid water content } \\ M & \text { Molecular weight } \\ \dot{m} & \text { mass flux } \\ \mathrm{Nu} & \text { Nusselt number } \\ P & \text { pressure } \\ P_{v} & \text { vapor pressure } \\ q & \text { heat flux } \\ r & \text { coefficient of restitution } \\ \mathrm{Re} & \text { Reynolds number } \\ \mathrm{Sc} & \text { Schmidt number } \\ \mathrm{Sh} & \text { Sherwood number } \\ \mathrm{St} & \text { mass Stanton number } \\ \mathrm{St} & \text { momentum Stanton number } \\ T & \text { temperature } \\ t & \text { time } \\ V & \text { velocity } \\ V_{c} & \text { critical velocity } \\ \beta & \text { collection efficiency } \\ \dot{\varepsilon} & \text { strain rate } \\ \lambda & \text { mass transfer parameter } \\ \mu & \text { viscosity } \\ \eta & \text { freezing fraction } \\ \rho & \text { density } \\ \sigma & \text { shear stress } \\ \tau_{m} & \text { dimensionless mass parameter } \\ \tau_{m o m} & \text { dimensionless momentum parameter } \\ \tau_{t} & \text { dimensionless thermal parameter } \\ \omega & \text { mass fraction } \\ & \end{array}$

Subscripts:

$\begin{array}{ll}\text { a } & \text { air } \\ \text { conv } & \text { convection } \\ \text { ev } & \text { evaporation } \\ \mathrm{f} & \text { freezing } \\ \text { film } & \text { film } \\ \text { heat } & \text { heat added } \\ \mathrm{i} & \text { ice } \\ \mathrm{KE} & \text { kinetic energy } \\ \mathrm{m} & \text { melting } \\ \mathrm{o} & \text { original } \\ \mathrm{rb} & \text { runback } \\ \mathrm{S} & \text { surface } \\ \mathrm{sens} & \text { sensible } \\ \mathrm{sub} & \text { sublimation } \\ \mathrm{t} & \text { threshold } \\ \mathrm{W} & \text { water } \\ \infty & \text { ambient }\end{array}$




\section{GlennICE Overview}

The GlennICE (Ref. 6) project was initiated in 1999 as a means to develop a consistent set of standards and practices for creation, use and maintenance of NASA administered icing computational tools. One goal of this process is to provide a mechanism for a more team-based approach to software development. Current development of icing codes at NASA has been more separated and individualbased. The plan has been to establish a common computational framework for integration of NASA icing analytical tools, and to create a set of requirements both for the development of these tools and for their integration into the common framework. The features of the resulting system would include providing a common user interface for all tools and allowing user selection of analysis modules. A modular design would allow more streamlined substitution of new or improved software elements, and the defined process would include documented standards for rapid integration of new software. This process also requires a version control system designed to allow both control of approved software and flexibility for rapid prototyping, as well as documentation that allows rapid identification of software design and use.

\section{NPSS Overview}

The Numerical Propulsion System Simulation (NPSS) code (Refs. 7 to 9) is used to model the thermodynamic cycle of complete aircraft engines and therefore can be effective at predicting the engine system operation. The development of this tool is a joint effort between NASA Glenn Research Center, the Department of Defense, and Unites States aeropropulsion industry. It is used to model the physical interactions between components of a turbine engine reducing the need for full-scale engine tests and component experiments ultimately impacting the time it takes to bring an aircraft engine to market.

At its core the NPSS is an object-oriented code that brings together multiple disciplines such as aerodynamics, structures, and heat transfer which supports multi-fidelity (numerical zooming) from zerodimensional to three-dimensional engine component codes. Zooming allows a designer to vary the level of detail of analysis throughout the engine based upon the physical processes being studied. It is important to consider the aircraft engine as a system of components interacting with each other not simply in isolation. In the NPSS these component models, potentially at various levels of fidelity, are allowed to interact with each other to see the effects they have on the overall engine performance. A simulation of a complete aircraft engine will provide sufficient detail of the individual components and their interactions with other engine components over a range of flight operating conditions. This allows for an examination of many design options before costly tests are conducted.

\section{GlennICE Modifications}

Three modifications have been made to GlennICE for handling ice particle impacts. First, there are the modifications to the particle trajectory routine that track the energy transfer to and from a particle. Second, there is a model for mass loss due to erosion in a mixed phase environment. Finally, there are changes to the mass and energy balance whereby the incoming ice particles can add to the ice mass at the surface. In addition to these modifications, an analysis was performed to assess if coupling between the air and ice phases is necessary.

There are two separate modifications to the particle trajectory equations in order to handle ice crystals. First, a separate drag equation is needed. The drag equation for liquid droplets includes an increase in drag due to particle deformation whereas ice crystals remain spherical. It is also assumes that ice crystals do not breakup due to shear. In addition, drag correlations were added for ice particles that are cylindrical as well as disk-shaped. The second modification was to track the change in particle temperature (and phase change if necessary) through the air stream. Previously, GlennICE did not track droplet temperature as they were assumed to be in equilibrium with the air. However, the mixed phase capabilities have been added to analyze engine ice events. In this scenario, the air, water drops and ice crystals will increase in temperature when they enter the engine. Since the air will respond more rapidly 
to this increase, there will exist a driving force for energy transfer between the particles and the surrounding air stream.

\section{Particle Drag Equations}

The following equations for particle drag were obtained by curve-fitting drag data for spheres, cylinders, and disks. The reference used was Perry's Chemical Engineers' Handbook (Ref. 10), but several references contain the same data.

For spheres

$$
\begin{array}{ll}
C_{d}=\frac{24}{\operatorname{Re}}+0.4+\frac{6}{1+\sqrt{\operatorname{Re}}} & \text { for } \operatorname{Re}<100 \\
C_{d}=\frac{24}{\operatorname{Re}}+0.3+\frac{6}{1+\sqrt{\operatorname{Re}}} & \text { for } \operatorname{Re}>100
\end{array}
$$

For cylinders

$$
\begin{array}{cc}
C_{d}=4.194 \mathrm{Re}^{-0.931} & \text { for } \mathrm{Re}<0.01 \\
C_{d}=13.344 \mathrm{Re}^{-0.691} & \text { for } 0.01<\mathrm{Re}<20 \\
C_{d}=3.2344-0.334 \log (\mathrm{Re}) & \text { for } 20<\mathrm{Re}<1000 \\
C_{d}=0.93 & \text { for } \mathrm{Re}>1000
\end{array}
$$

For disks

$$
\begin{gathered}
C_{d}=\frac{24}{\operatorname{Re}}+0.4+\frac{6}{1+\sqrt{\operatorname{Re}}} \quad \text { for } \operatorname{Re}<40 \\
C_{d}=1.5 * 10^{-6} \operatorname{Re}^{2}+0.001 \operatorname{Re}+1.8176 \quad \text { for } 40<\operatorname{Re}<1000 \\
C_{d}=1.3 \quad \text { for } \operatorname{Re}>1000
\end{gathered}
$$

\section{Particle Energy Balance}

The following analysis will present the energy equation for a spherical ice particle. The particle energy equation is simply the increase or decrease in enthalpy of the particle balanced with the losses due to convection and sublimation or

$$
\frac{\partial H}{\partial t}=q_{\mathrm{conv}}+q_{\mathrm{sub} / \mathrm{evap}}
$$

Prior to or after any phase change by melting of the ice crystal, this equation can be given as 


$$
\rho_{i} C_{p, i} \frac{\pi d^{3}}{6} \frac{\partial T_{s}}{\partial t}=h \pi d^{2}\left(T_{a}-T_{s}\right)+\pi d^{2} \rho_{a} h_{m} L_{\mathrm{sub}}\left(\omega_{a}-\omega_{s}\right)
$$

for spheres

After a particle has started to change phase, $L_{\text {sub }}$ is replaced by $L_{\text {evap }}$ in the equation above. It will be more convenient to solve this equation in non-dimensional form, hence

$$
\begin{gathered}
\mathrm{Nu}=\frac{h d}{k_{a}} \\
\mathrm{Sh}=\frac{h_{m} d}{D_{a, i}} \\
\mathrm{Pr}=\frac{C_{p, a} \mu_{a}}{k_{a}} \\
\mathrm{Sc}=\frac{\mu_{a}}{\rho_{a} D_{a, i}} \\
\omega=\frac{M_{w}}{M_{a}} \frac{P_{v}}{P} \\
\tau_{T}=\frac{C_{p, i} \rho_{i} d^{2}}{12 k_{a}}
\end{gathered}
$$

The resulting energy equation then becomes

$$
\frac{d T_{S}}{d t}=\frac{\mathrm{Nu}}{2 \tau_{T}}\left(T_{a}-T_{S}\right)+\frac{\mathrm{Sh}}{2 \tau_{T}} \frac{\operatorname{Pr}}{\operatorname{Sc}} \frac{L_{\mathrm{sub}}}{C_{p, i}}\left(\omega_{\infty}-\omega_{S}\right)
$$

where

For spherical particles

$$
\begin{aligned}
& \mathrm{Nu}=2+0.6 \operatorname{Re}^{1 / 2} \operatorname{Pr}^{1 / 3} \\
& \mathrm{Sh}=2+0.6 \mathrm{Re}^{1 / 2} \mathrm{Sc}^{1 / 3}
\end{aligned}
$$

where

$$
\operatorname{Re}=\frac{\rho_{a}\left|V_{a}-V_{i}\right| d}{\mu_{a}}
$$

For cylindrical particles 


$$
\begin{gathered}
\mathrm{Nu}=0.3+0.62 \operatorname{Re}^{1 / 2} \operatorname{Pr}^{1 / 3} \frac{\left(1+\left(\frac{\mathrm{Re}}{2.82 * 10^{5}}\right)^{0.625}\right)^{0.8}}{\left(1+\left(\frac{0.4}{\mathrm{Pr}}\right)^{2 / 3}\right)^{1 / 4}} \\
\mathrm{Sh}=0.3+0.62 \operatorname{Re}^{1 / 2} \operatorname{Sc}^{1 / 3} \frac{\left(1+\left(\frac{\mathrm{Re}}{2.82 * 10^{5}}\right)^{0.625}\right)^{0.8}}{\left(1+\left(\frac{0.4}{\mathrm{Sc}}\right)^{2 / 3}\right)^{1 / 4}}
\end{gathered}
$$

For discs

$$
\begin{array}{cr}
\mathrm{Nu}=0.664 \mathrm{Re}^{1 / 2} \operatorname{Pr}^{1 / 3} & (\mathrm{Re}<200,000) \\
\mathrm{Nu}=\frac{0.037 \mathrm{Re}^{0.8} \mathrm{Pr}}{1+2.443 \mathrm{Re}^{-0.1}\left(\operatorname{Pr}^{2 / 3}-1\right)} & (\operatorname{Re}>200,000) \\
\mathrm{Sh}=0.664 \mathrm{Re}^{1 / 2} \mathrm{Sc}^{1 / 3} & (\operatorname{Re}<200,000) \\
\mathrm{Sh}=\frac{0.037 \mathrm{Re}^{0.8} \mathrm{Sc}}{1+2.443 \mathrm{Re}^{-0.1}\left(\mathrm{Sc}^{2 / 3}-1\right)} & (\operatorname{Re}>200,000)
\end{array}
$$

Reduction in particle size for a sphere is given by the mass balance

$$
\rho_{i} \frac{\partial}{\partial t}\left(\frac{\pi d^{3}}{6}\right)=\operatorname{Sh} \pi d^{2} \rho_{a} D_{a, i} \frac{\omega_{a}-\omega_{s}}{d}
$$

or after integration

$$
\begin{gathered}
d^{2}=d_{o}^{2}-\lambda t \\
\lambda=\frac{4 \operatorname{Sh} \rho_{a} D_{a, i}}{\rho_{i}}\left(\omega_{s}-\omega_{\infty}\right)
\end{gathered}
$$
by

During phase change, the ice/water temperature remains fixed and the rate of melting of ice is given

$$
\rho_{i} L_{f} \frac{\pi d^{3}}{6} \frac{\partial \eta}{\partial t}=h \pi d^{2}\left(T_{a}-T_{m}\right)+\pi d^{2} h_{m} L_{\text {evap }}\left(\omega_{a}-\omega_{m}\right)
$$


By fixing the crystal temperature at the melting point, the melting rate can be calculated directly from this equation.

\section{Coupling Between Particles and Air}

In previous icing analysis, the airflow and particle dynamics were calculated separately, which implies that coupling of the equations are unnecessary. In this regime, it should be clarified whether or not coupling is needed. Crowe (Ref. 11) estimated mass coupling to be important if

$$
\frac{Z}{\mathrm{St}_{m}}>1
$$

where

$$
\begin{gathered}
Z=\frac{\mathrm{IWC}}{\rho_{a}} \\
\mathrm{St}_{m}=\frac{\tau_{m} V_{i}}{L} \\
\tau_{m}=\frac{\rho_{i} d^{2}}{6 \operatorname{Sh} \rho_{a} D_{a, i}\left(\omega_{s}-\omega_{\infty}\right)}
\end{gathered}
$$

If we try to maximize the coupling, we need the maximum ice water content, the smallest particle size, the lowest ice velocity, the longest compressor length and the highest mass transfer rate. Let IWC $=$ $9 \mathrm{~g} / \mathrm{m}^{3}, d=15 \mu \mathrm{m}, V_{\text {ice }}=40 \mathrm{~m} / \mathrm{s}, P=27,000 \mathrm{~Pa}, \mathrm{Sh}=5, L=1.4 \mathrm{~m}$ and $\left(\omega_{\mathrm{s}}-\omega_{\infty}\right)=0.02$ then $\rho_{a}=0.4, \tau_{m}=$ 0.044 and $\frac{Z}{\mathrm{St}_{m}}=0.018$, thus mass coupling is unimportant.

Momentum coupling is important when

$$
\frac{Z}{1+\mathrm{St}_{\text {mom }}}>1
$$

where

$$
\begin{gathered}
\mathrm{St}_{\text {mom }}=\frac{\tau_{v} V_{i}}{L} \\
\tau_{v}=\frac{\rho_{d} d^{2}}{18 \mu_{a}}
\end{gathered}
$$

thus using the previous values,

$$
\begin{gathered}
\tau_{v}=0.000744 \\
\mathrm{St}_{\text {mom }}=0.021 \\
Z=0.0225 \frac{0.0225}{1+0.021}=0.022
\end{gathered}
$$


so momentum coupling can be ignored.

Energy coupling is given by

$$
\frac{Z}{\mathrm{St}_{m}} \frac{L_{\mathrm{sub}}}{C_{p, i} T}=0.1
$$

using the previous values so energy coupling is unimportant as well. Based on this analysis, the one-way coupling performed in icing software such as GlennIce is still justified.

\section{Coefficient of Restitution}

When a solid particle hits a surface, the resulting collision is considered elastic or inelastic. If the collision is elastic, none of the incoming energy is absorbed by the surface. For inelastic collisions, some of the energy is absorbed by the surface and some is used to determine the velocity of the particle after the collision. This energy ratio is called the coefficient of restitution. If this coefficient is equal to one, the collision is considered elastic. If this coefficient is equal to zero, all of the energy is absorbed by the surface. In this case, all of the mass must remain on the surface as well. Therefore, in the ice crystal environment being modeled, the coefficient of restitution can be used to determine the fraction of impinging ice crystals that remain on the surface, similar to the splashing model used for supercooled large droplets. Higa et al. (Ref. 12) measured the coefficient of restitution for an ice sphere with a $3 \mathrm{~cm}$ diameter at velocities up to $0.7 \mathrm{~m} / \mathrm{s}$ and a wide range of temperatures. They curve-fit the restitution coefficient to the following equation:

$$
r=\left(\frac{V}{V_{c}}\right)^{-\log \left(\frac{V}{V_{c}}\right)}
$$

They reported values of the critical velocity $\left(V_{c}\right)$ after which particle collisions were no longer quasielastic at velocities of 25,35 , and $61 \mathrm{~cm} / \mathrm{s}$ at 269,261 , and $245 \mathrm{~K}$, respectively. The decrease in restitution coefficient was caused by fragmentation of the ice spheres. Based on this equation, most ice particle collisions at the surface will have essentially a zero restitution coefficient, meaning that almost all of the energy of the collision is transferred to the surface and the ice crystals are expected to fragment. Initial build up of an ice layer is then caused in part by the kinetic energy of the collision being used to melt the surface ice fragments. GlennICE assumes that the fraction of ice crystals present on the surface will be (1-r) as this is the fraction of energy transferred to the surface during the collision with the surface. However, this does not necessarily mean that the ice crystals will accumulate. In order for accretion to occur, a film thickness must be present. Otherwise, the ice fragments would be swept away by the flow field. In the limited mixed phase experiments presented below, the ice crystals do not accumulate even in a glaze ice condition where a water film is present. However in this case the water film is limited to a very small region near the stagnation zone. In the current model, the energy and mass balances are calculated assuming the ice crystals remain on the surface. For control volumes that do not have a liquid film, the ice crystal mass is removed prior to the geometry modification routines. As more experimental data becomes available, this assumption can be revisited. Erosion effects, as described below, are accounted for in all regimes.

\section{Ice Erosion}

Ice erosion occurs when ice particles hit an ice shape that has already accreted. The force of impact can dislodge portions of the ice shape, especially individual ice feathers. Al-Khalil (Ref. 5) performed tests in the Cox icing tunnel in order to document the mixed phase capabilities of that facility. The model 
was a 36 in. chord NACA0012 airfoil. All cases were run for $10 \mathrm{~min}$. at $100 \mathrm{kts}, \alpha=0^{\circ}$ and a water MVD $=20 \mu \mathrm{m}$. Results from Al-Khalil's report show that ice impacts can cause erosion of an ice shape in a mixed phase test. Four cases were selected for calibration with the GlennICE erosion model. The cases are given in Table 1.

The cases at the lower temperature (cases 3 and 4) were unaffected by the ice crystals as the ice thickness compares well with values from GlennICE without any erosion effects. This suggests that the low air speed of these conditions is not high enough to cause erosion. At the warmer condition (cases 14 and 15), the introduction of an IWC of $0.7 \mathrm{~g} / \mathrm{m}^{3}$ caused a 20 percent reduction in the ice shape as shown in Figure 1. The amount of ice loss was calculated using the utility program THICK. This result seems to indicate that the lower bonding strength of the ice at the warmer condition is enough to cause the onset of ice erosion. Rist (Ref. 13) measured the deformation and fracture of $1.5 \mathrm{~cm}$ ice particles over a wide range of temperatures. He measured the strain rate at failure to the corresponding stress applied and produced the following relationship:

$$
\dot{\varepsilon}=\left(\sigma_{1}-\sigma_{3}\right)^{4.2} \exp \left(14-\frac{Q}{R T}\right)
$$

In this equation, $Q$ is the activation energy that was measured as $69 \mathrm{~kJ} / \mathrm{mol}$ in the experiment and $R$ is the gas constant. For the cases listed, the warmer condition would require only half as much force to produce the same strain rate in the ice as the colder temperature cases. The impacting force of each particle is proportional to the mass of the particle (and thus proportional to the diameter cubed), the velocity and the particle frequency. Without performing a stress analysis of each ice shape there is insufficient data to build a proper correlation due to the sparseness of the test matrix. However if it is assumed that the cases without erosion effect are at the erosion threshold, the erosion effect can be estimated. First, the impact stress was assumed proportional to the force of the ice particle impacts. This force was determined by multiplying the particle momentum with the frequency:

$$
F=\left[\frac{\pi}{6} \rho_{i} d^{3}\right] V\left[\frac{V}{d}\left(\frac{\mathrm{IWC}}{\rho_{i}}\right)^{\frac{1}{3}}\right]
$$

The term in the second bracket is the particle frequency. This equation would make the stress proportional to $d^{2}, V^{2}$, and IWC ${ }^{1 / 3}$. This would make the applied stress the same for the cases where IWC $=0.7 \mathrm{~g} / \mathrm{m}^{3}$. However, since the temperature is higher in case 15 than case 3 , twice as much strain rate is produced in the ice, causing a 20 percent reduction in ice size. The model in GlennICE first assumes that case 4 from the Al-Khalil data is at the threshold where erosion becomes important. For this condition and for conditions with lower shear stresses due to particle impact, no erosion takes place. For conditions with higher impact energy, the ratio of strain rate can be estimated by

$$
\frac{\dot{\varepsilon}}{\dot{\varepsilon}_{t}} \approx\left(\frac{d}{d^{t}}\right)^{2}\left(\frac{V}{V_{t}}\right)^{2}\left(\frac{\mathrm{IWC}}{\mathrm{IWC}_{t}}\right)^{1 / 3}\left(\frac{\exp \left(14-\frac{Q}{R T}\right)}{\exp \left(14-\frac{Q}{R T_{t}}\right)}\right)
$$

The erosion threshold values are $d_{t}=150 \mu \mathrm{m}, V_{t}=100 \mathrm{kts}, \mathrm{IWC}_{t}=0.7 \mathrm{~g} / \mathrm{m}^{3}$, and $T_{t}=267 \mathrm{~K}$ which is the average ice temperature in the impingement region for this condition. If it is further assumed that the erosion rate is proportional to the increase in strain rate, the erosion rate can then be related back to the incoming conditions. Comparing case 4 with case 15 from Al-Khalil's data gives: 


$$
\frac{\dot{\varepsilon}}{\dot{\varepsilon}_{t}} \approx\left(\frac{200}{150}\right)^{2}\left(\frac{100}{100}\right)^{2}\left(\frac{0.7}{0.7}\right)^{1 / 3}\left(\frac{\exp \left(14-\frac{69}{8.314 * 10^{-3} * 273}\right)}{\exp \left(14-\frac{69}{8.314 * 10^{-3} * 267}\right)}\right)=3.5
$$

Given that case 4 does not appear to have any erosion effects while case 15 shows a 20 percent loss in mass due to erosion leads to the following empirical equation:

$$
\text { erosion }=0.08\left(\frac{\dot{\varepsilon}}{\dot{\varepsilon}_{t}}-1\right)
$$

where $\dot{\varepsilon}_{t}$ is the strain rate at the erosion threshold. Obviously, much more data would be necessary to determine a more accurate value for the erosion threshold as well as to verify the dependence of erosion on the icing parameters.

\section{Surface Energy Balance}

The mass and energy balance add terms for the added mass of ice, the kinetic impact of the ice particles, and the melting of ice crystals. For a glaze surface,

$$
\dot{m}_{\mathrm{imp}, \mathrm{w}}+\dot{m}_{\mathrm{imp}, \mathrm{i}}=\dot{m}_{f}+\dot{m}_{\mathrm{rb}}+\dot{m}_{\mathrm{ev}}+\dot{m}_{\mathrm{sub}}+\dot{m}_{\mathrm{film}}
$$

where

$$
\dot{m}_{\mathrm{imp}, \mathrm{i}}=(1-\text { erosion })(1-r) \beta_{i} \mathrm{IWC} V
$$

$r$ is the restitution coefficient calculated earlier.

The energy equation becomes

$$
q_{\mathrm{f} / \mathrm{m}}+q_{\text {heat }}+q_{\mathrm{KE}, \mathrm{a}}+q_{\mathrm{KE}, \mathrm{w}}+q_{\mathrm{KE}, \mathrm{i}}-q_{\mathrm{conv}}-q_{\mathrm{evap}}-q_{\mathrm{sub}}-q_{\mathrm{sens}}=0
$$

where $q_{\mathrm{f} / \mathrm{m}}$ is the heat removed by additional freezing or heat added by melting of ice. As described below, GlennICE assumes that only one of these processes can take place in a particular control volume.

The first term that is added due to ice crystal impacts is the kinetic energy transfer of the impacting crystals,

$$
q_{\mathrm{KE}, \mathrm{i}}=\frac{1}{2} \dot{m}_{\mathrm{imp}, \mathrm{i}} V_{\mathrm{imp}}^{2}(1-r)
$$

where $r$ is the restitution coefficient calculated earlier. The second term added is the melting term given above. The final term that is changed is the sensible heat transfer from the drop or particle. Previously, the drops were assumed to be at the ambient air temperature. Currently, the particle temperature is calculated as shown earlier and the resulting temperature at impact is transferred to the icing balance. In addition, any phase change or changes in particle and droplet size are accounted for in these equations.

In the solution procedure, the terms other than melting and freezing are summed. Based on the sign of that term, the remaining energy is used to either freeze additional surface water or used to melt incoming ice. In a situation where more energy is carried away allowing additional freezing, then the freezing fraction of the incoming ice crystals is equal to one and the additional freezing fraction of the incoming water is calculated from the energy balance. In a situation where more energy is available to melt the incoming ice, then the freezing fraction of the incoming water is zero and the fraction of incoming ice that 
is melted is again calculated from the energy equation. In any situation where the sum of the other terms is exactly zero, then the freeing fraction of the incoming water is zero and the freezing fraction of the incoming ice is equal to one. The solution procedure determines the mass of ice or water directly and does not rely on calculating a freezing fraction.

\section{Results}

The energy efficient engine, or $\mathrm{E}^{3}$, was designed at NASA Glenn for the intention to lay an advanced technology foundation for a new generation of turbofan engines. It was a cooperative program with industry aimed at developing and demonstrating advanced component and systems technologies for engines. Since the geometry is public domain, it was selected for initial tests of the computer model. Figure 2 shows a top view of this engine while Figure 3 shows the cross-section.

The NPSS code was used to fly the $\mathrm{E}^{3}$ engine over a typical flight envelope to determine locations in the engine where ice accretion might occur. The flight envelope provided the NPSS code with the altitude and throttle settings for the engine performance analysis. The NPSS code was used in a 0-D (thermodynamic cycle analysis) mode to determine locations in the compression system where ice accretion might be supported. Figure 4 illustrates the total temperature variation over a portion of the flight envelope for the $\mathrm{E}^{3}$ at engine station 2.2. Based on icing event statistics of commuter and large transport aircraft reported by Mason (Ref. 1), the $\mathrm{E}^{3}$ was flown over the flight envelope at various altitude and temperatures (at and above standard atmospheric conditions). The representative flight envelope shown in Figure 4 includes two cruise altitudes and one descent profile. During the two cruise portions of the flight, the engine operates at reduced thrust after attaining the desired altitude. At the end of the second cruising altitude, the engine is spooled back to 5 percent maximum thrust in preparation for descent. The aircraft then descends from maximum cruising altitude to prepare for landing at a reduced thrust. An engine operating point at $22 \mathrm{R}$ above standard atmospheric conditions within the $39000 \mathrm{ft}$ cruise portion of the flight envelope was selected for testing GlennICE. Figure 5 shows the fan tip performance map of the engine at the elevated temperature. The fan operates well away from the surge line over the flight profile. However as indicated in Figure 6, the fan hub and quarter stage compression system operates near the surge line and with geometry changes due to ice accretion has the potential to push the compression system toward surge thus compromising the engine performance and causing a safety concern.

The initial analysis performed for this report focuses on the region from the inlet through the lowpressure compressor (LPC) to the entrance of the high-pressure compressor (HPC). The system modeled in NPSS using a 0-D analysis was used to obtain temperature, pressure, and flow rates at various engine stations. A diagram of the region analyzed is shown in Figure 7 and the results of the NPSS analysis at the selected location in the flight envelope are shown in Table 2.

A zero-order analysis only provides values at specific locations such as the conditions before and after the fan for example. It does not include the dimensions of the system, hence the use of the term zeroorder. While NPSS is capable of performing a higher fidelity model, the zero-order results were sufficient for the purposed of testing the initial model. In order to use this information in GlennICE, a grid was created in GRIDGEN and the values from Table 2 were used to supply velocities, pressures, and temperatures at the grid points. Since a flow analysis was not performed using this grid, it can be somewhat coarser than that used for Navier-Stokes analysis since its only purpose is for tracking particle trajectories. There were 10 grid blocks used with a total of 19,000 grid points in order to interpolate the NPSS results to a grid that GlennICE could use. Spherical ice crystals of $200 \mu \mathrm{m}$ MVD were then tracked through this artificial flow field to find collection efficiencies on the two splitters. This is shown in Figure 8.

The secondary splitter had minimal impingement and no ice growth, so results for that geometry are not shown. An icing time of $5 \mathrm{~min}$ and an IWC of $8 \mathrm{~g} / \mathrm{m}^{3}$ were used to generate the results for this case. Velocity, temperature and pressure were taken as the conditions at the engine inlet as shown in Table 1. Results from the energy balance and mass balance are shown in Figures 9 and 10, respectively. Figure 11 
shows what the ice shape would look like without erosion effects. Based on the preliminary ice erosion model used, this ice shape would be completely eroded by the impact of other ice crystals due to the much higher velocities inside the engine. It should be emphasized that this result has not been experimentally verified.

\section{Future Work}

This model must be considered at the early stages of development at this juncture. Much work remains in order to produce a model ready for release. In particular, experimental data is needed to verify erosion effects and the deposition rate of ice crystals when a water film is present. Just as early research in the supercooled droplet regime provided references of droplet splashing at low velocities that did not coincide with results obtained in the NASA icing tunnel at higher velocities, the models presented in this report for coefficient of restitution, particle breakup and ice erosion at low velocities need to be confirmed at the higher velocities inside the engine. In addition, while particles impinge on the lower wall of the input geometry (shown in Fig. 7), GlennICE needs to be modified to allow deposition and accretion on this surface. Experimental data on actual engine geometries in an ice crystal environment is also necessary for validation. It would also be useful to test the model with two-dimensional flow solutions from NPSS. Once a viable model is ready, it will also be implemented into LEWICE3D so that the full geometry can be analyzed.

\section{Conclusions}

A preliminary model for multiphase ice accretion was developed for GlennICE. An analysis of typical ice crystal inputs showed that one-way coupling could still be used in the icing model. The effects of temperature change, phase change and sublimation of the ice crystal were added to the trajectory model. In addition, non-spherical ice crystal capability was also added. A factor for the coefficient of restitution was also added. The energy equation was revised to include the effects of ice crystals, including a preliminary model for ice erosion. Erosion results were calibrated to a mixed phase icing test performed by Al-Khalil in the Cox icing facility. Icing results were produced for a test case using the $\mathrm{E}^{3}$ geometry. The results show that while ice could form on the splitter lip based on the energy balance, it would be quickly eroded by other ice particle impacts. However, this result has not been experimentally validated.

\section{References}

1. Mason, J.G., Strapp, J.W., and Chow, P., "The Ice Particle Threat to Engines in Flight," AIAA-2006-206.

2. Venkataramani, K.S., Plybon, R.C., Holm, R.G., and Krupp, B.R., "Aircraft Engine Icing Model," AIAA-2008-440.

3. Veillard, X., Habashi, W.G., Aube, M.S., and Baruzzi, G.S., "FENSAP-ICE: Ice Accretion in Multistage Jet Engines," AIAA-2009-4158.

4. Rios, M.A., and Cho, Y.I., "Analysis of Ice Crystal Ingestion as a Source of Ice Accretion inside Turbofans," AIAA-2008-4365.

5. Al-Khalil, K., "Assessment of Effects of Mixed Phase Icing Conditions on Thermal Protection Systems," DOT/FAA/AR-03/48, May, 2003.

6. Wright, W.B., Potapczuk, M.G., and Levinson, L.H., "Comparison of LEWICE and GlennICE in the SLD Regime," AIAA-2008-0439.

7. Lytle, J.K., "The Numerical Propulsion System Simulation: An Overview," NASA/TM-2000209915.

8. Jones, Scott M., "An Introduction to Thermodynamic Performance Analysis of Aircraft Gas Turbine Engine Cycles Using the Numerical Propulsion System Simulation Code," NASA/TM-2007214690. 
9. Turner, Mark G.; Reed, John A.; Ryder, Robert; Veres, Joseph P., "Multi-Fidelity Simulation of a Turbofan Engine With Results Zoomed Into Mini-Maps for a Zero-D Cycle Simulation," NASA/TM-2004-213076.

10. Green, D.W., Perry's Chemical Engineer's Handbook, $6^{\text {th }}$ Edition, Sect. 5, pg. 54.

11. Higa, M., Arakawa, M., Maeno, N., "Measuremens of Restitution Coefficients of Ice at Low Temperatures," Planet. Space Sci, vol. 44, no. 9, pp. 917-925, 1996.

12. Crowe, C., Sommerfeld, M. and Tsuji, Y., Multiphase Flows with Droplets and Particles, CRC Press, 1998.

13. Rist, M.A., and Murrell, S.A.F., "Ice Triaxial Deformation and Fracture, J. of Glaciology," v. 40, no. 135 , pp. $305-18,1994$.

TABLE 1.-MIXED PHASE ICING RUNS

\begin{tabular}{|c|c|c|c|c|}
\hline Case no. & $\begin{array}{c}T_{o}, \\
{ }^{\circ} \mathrm{F}\end{array}$ & $\begin{array}{c}\text { MVD, ice, } \\
\mu \mathrm{m}\end{array}$ & $\begin{array}{c}\text { IWC, } \\
\mathrm{g} / \mathrm{m}^{3}\end{array}$ & $\begin{array}{c}\text { LWC, } \\
\mathrm{g} / \mathrm{m}^{3}\end{array}$ \\
\hline 3 & 12 & 150 & 0.3 & 0.7 \\
\hline 4 & 12 & 150 & 0.7 & 0.3 \\
\hline 14 & 22 & N/A & 0 & 0.7 \\
\hline 15 & 22 & 200 & 0.7 & 0.7 \\
\hline
\end{tabular}

TABLE 2.-FLOW CONDITIONS FROM NPSS ZERO-ORDER ANALYSIS

\begin{tabular}{|c|c|c|c|c|c|}
\hline Station & $\begin{array}{c}T, \\
\mathrm{R}\end{array}$ & $\begin{array}{c}P, \\
\mathrm{psia}\end{array}$ & Mach & $\begin{array}{c}V, \\
\mathrm{mph}\end{array}$ & $\begin{array}{c}W, \\
\mathrm{lbm} / \mathrm{s}\end{array}$ \\
\hline 1 & 462.2 & 4.27 & 0.78 & 776.4 & 1313.3 \\
\hline 2 & 462.2 & 4.27 & 0.57 & 580.2 & 1313.3 \\
\hline $2 \mathrm{~T}$ & 462.2 & 4.27 & 0.57 & 580.2 & 1017.5 \\
\hline $2 \mathrm{H}$ & 462.2 & 4.27 & 0.57 & 580.2 & 295.8 \\
\hline 21 & 513.3 & 5.94 & 0.48 & 520.0 & 224.0 \\
\hline 22 & 530.7 & 6.67 & 0.48 & 534.6 & 202.8 \\
\hline 23 & 530.7 & 6.67 & 0.48 & 534.6 & 96.6 \\
\hline 24 & 530.7 & 6.67 & 0.21 & 240.0 & 106.2 \\
\hline 25 & 530.7 & 6.67 & 0.40 & 439.8 & 106.2 \\
\hline 13 & 527.4 & 6.47 & 0.46 & 502.5 & 716.3 \\
\hline 14 & 527.4 & 6.47 & 0.48 & 526.1 & 716.3 \\
\hline 15 & 527.4 & 6.50 & 0.48 & 531.4 & 813.0 \\
\hline
\end{tabular}




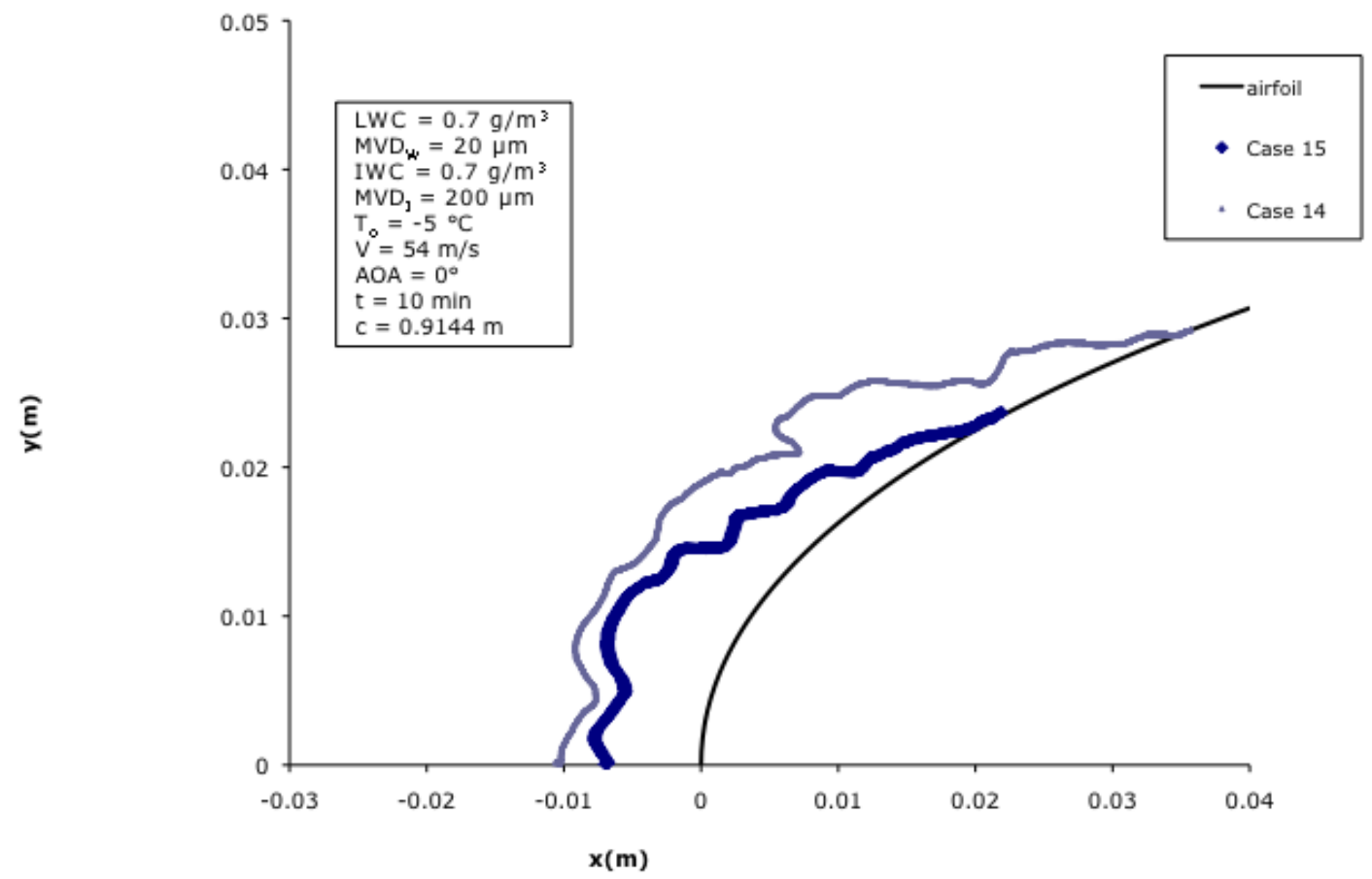

Figure 1.-Erosion effect with mixed phase inputs.

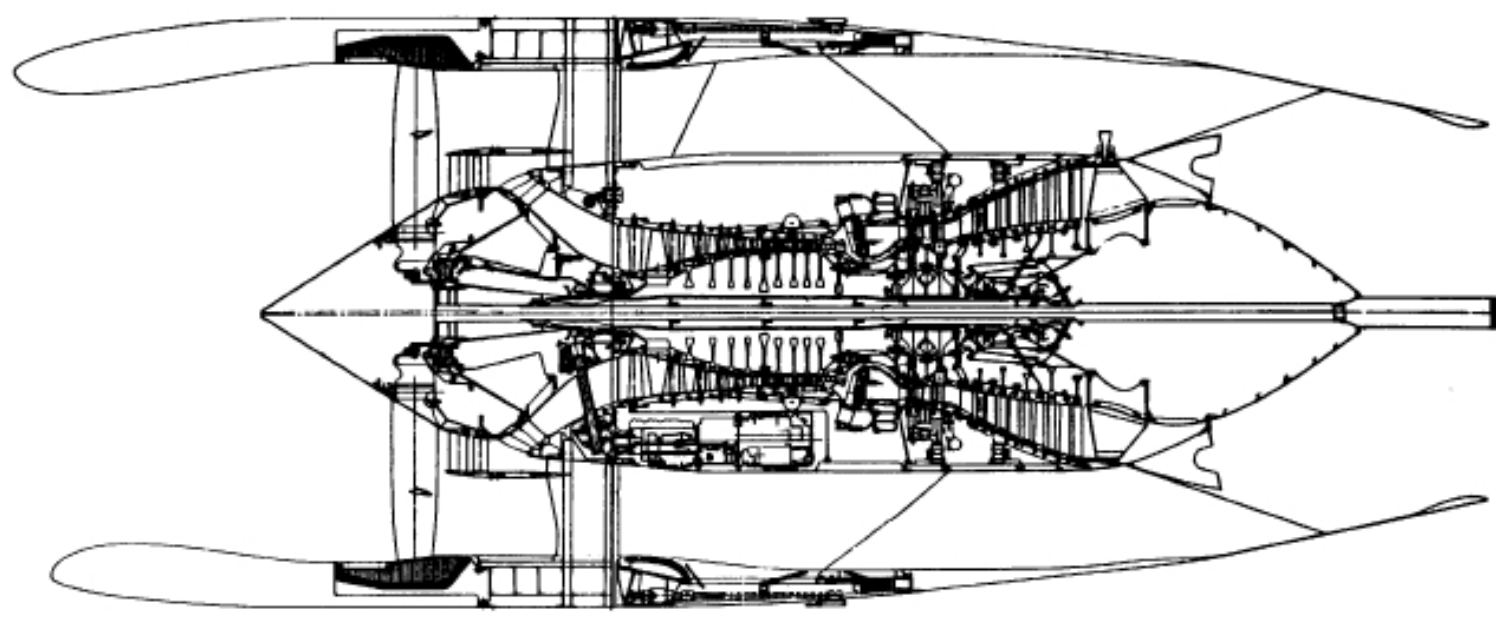

Figure 2.-Top view of energy efficient engine. 


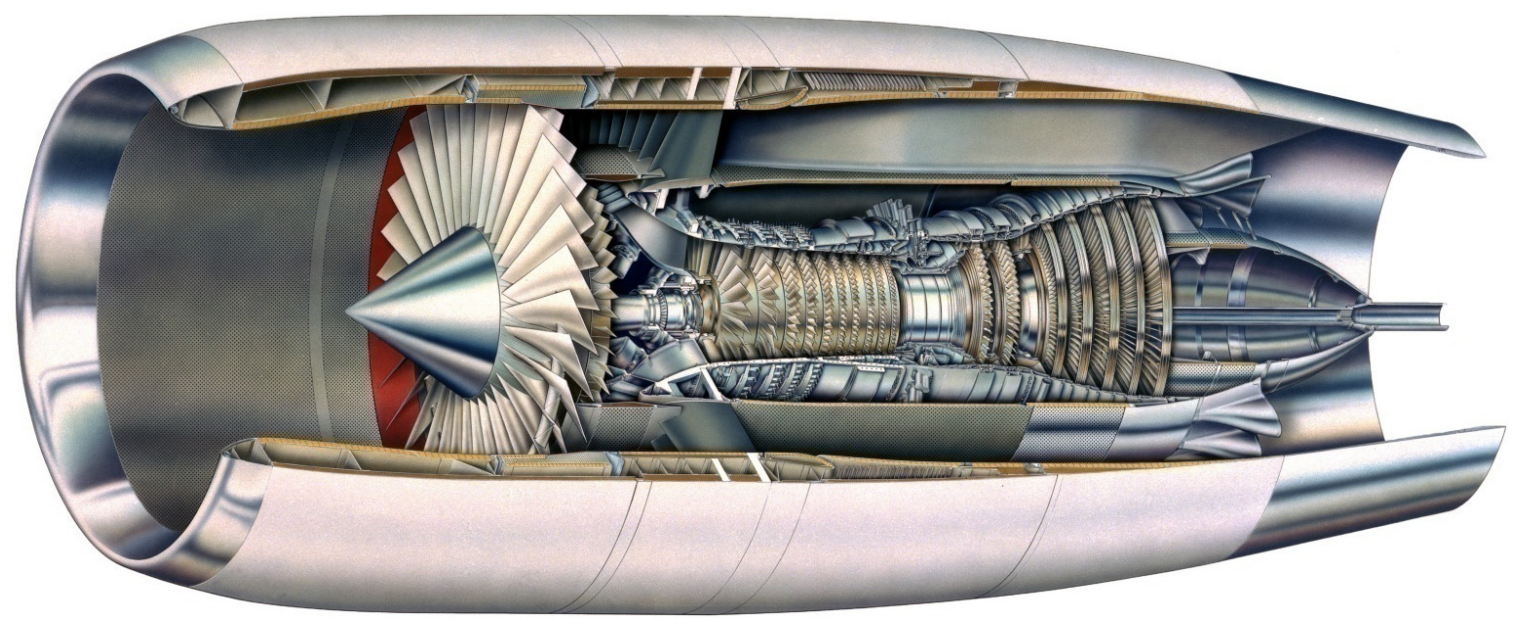

Figure 3.-Cross-section view of energy efficient engine.

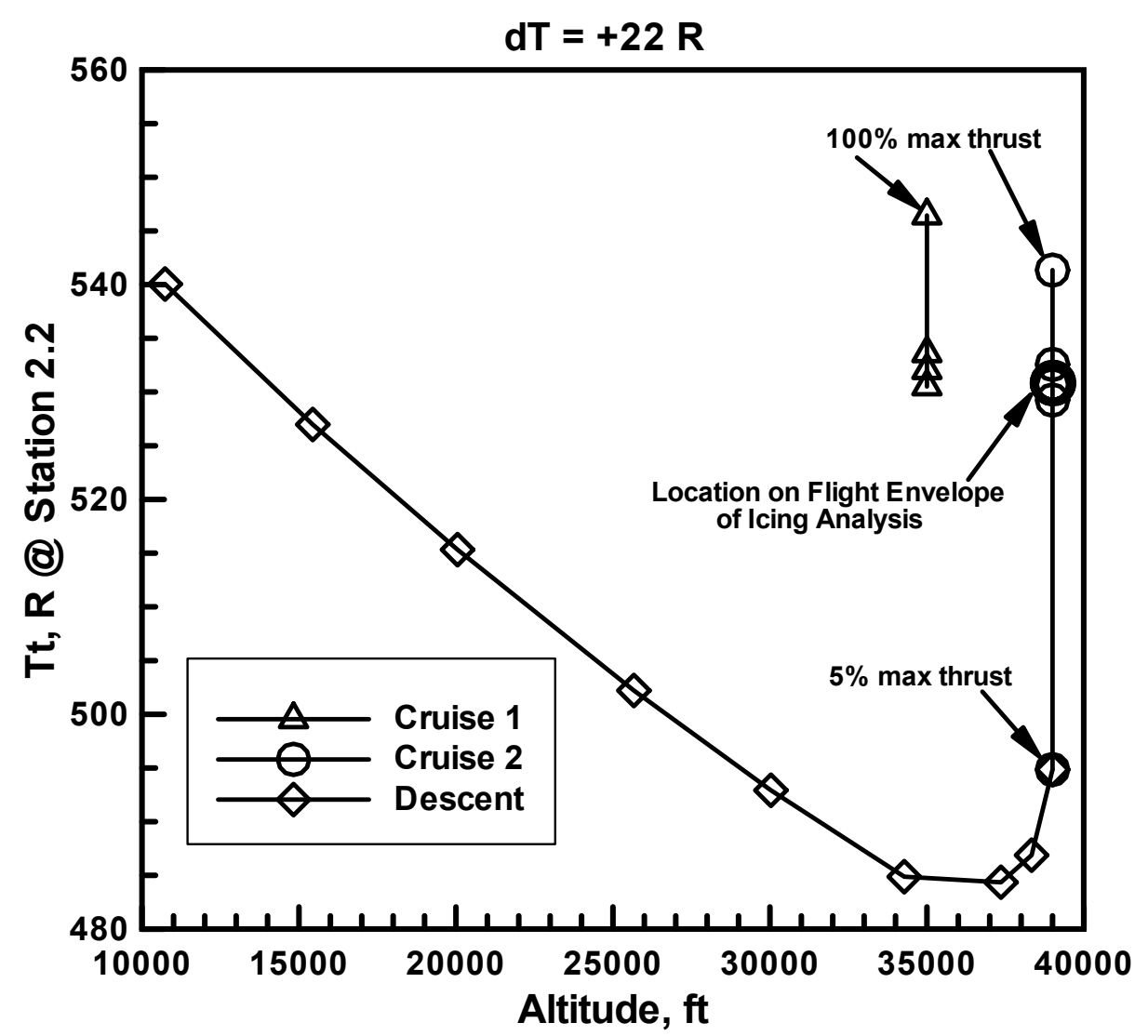

Figure 4.-Total temperature range at engine station 2.2 of the $E^{3}$ over a prescribed flight envelope at $22 \mathrm{R}$ above standard atmospheric conditions. Engine operating point in cruise at $39000 \mathrm{ft}$ was selected for testing GlennICE. 


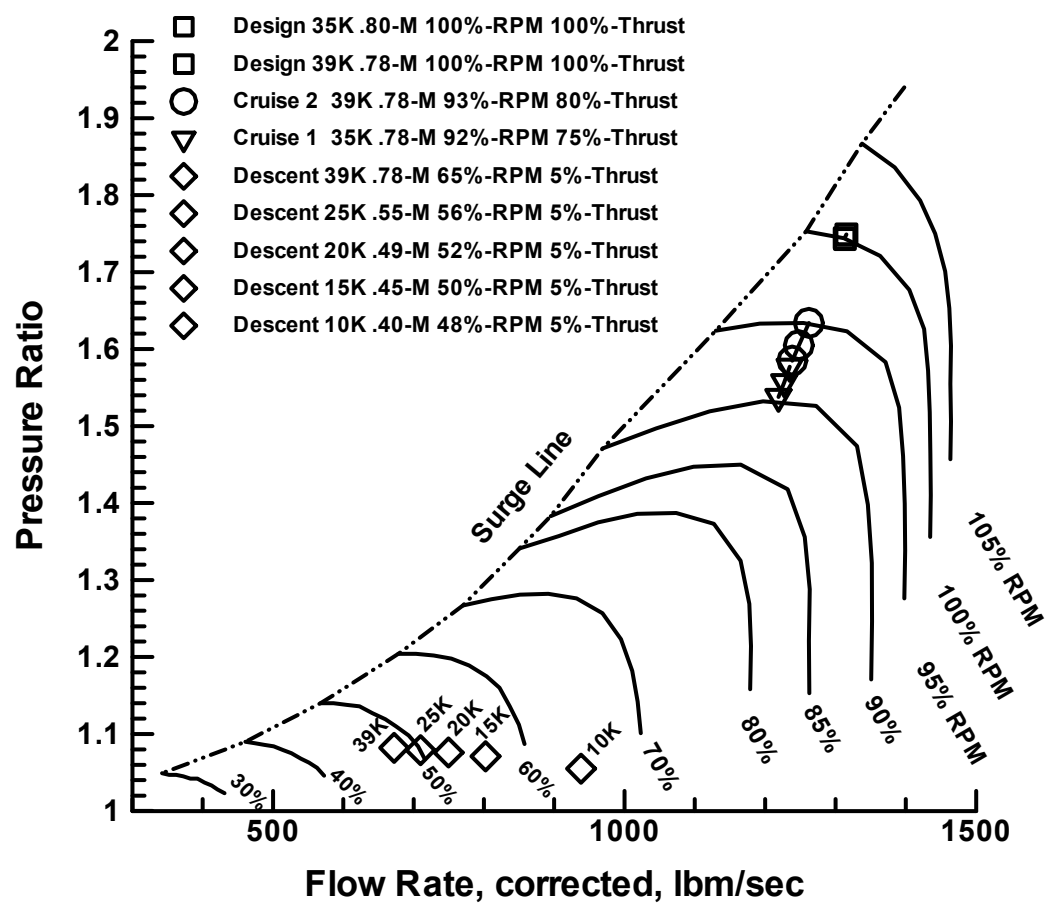

Figure 5.-Fan tip performance map showing corrected flow rate versus total pressure ratio, for a range of corrected speed lines. Key engine operating points along the vehicle trajectory are superimposed onto the fan map. Corrected speed lines are expressed as a percent of the design rotational speed.

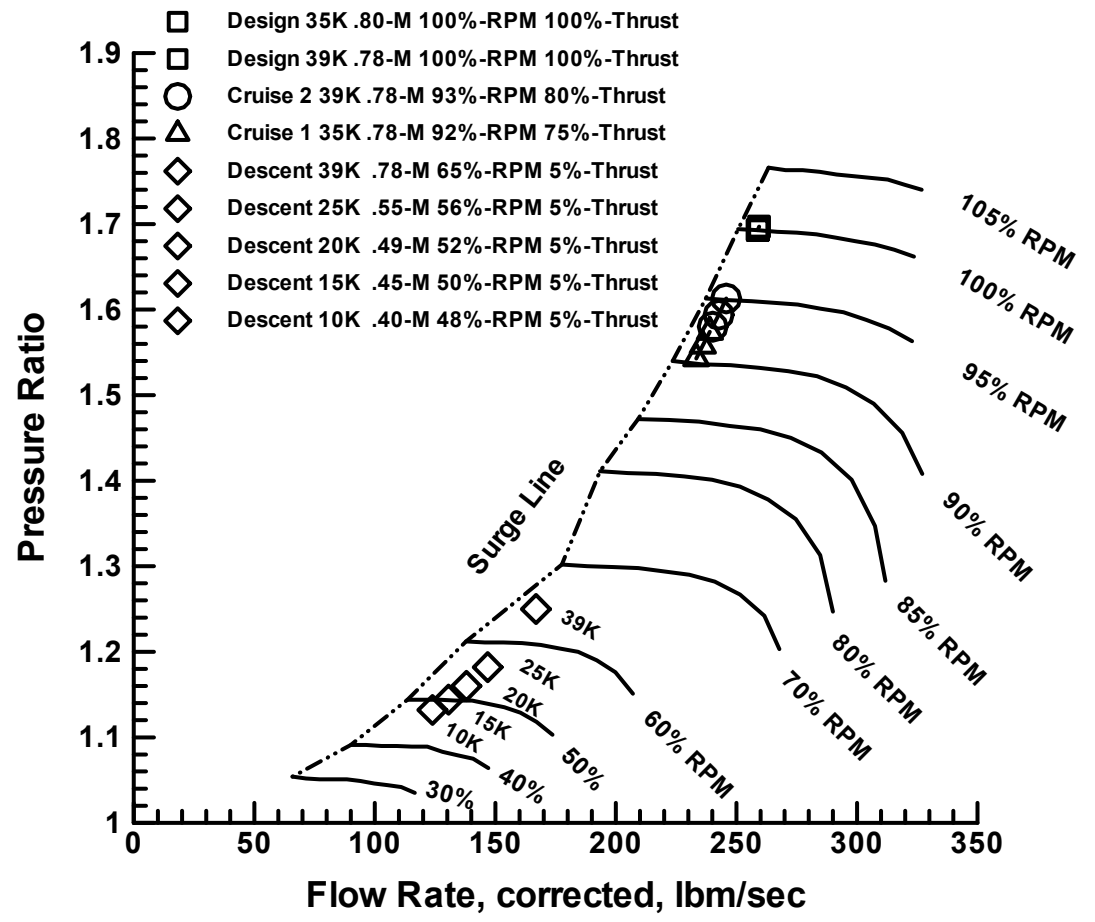

Figure 6.-Fan hub and quarter stage performance map showing corrected flow rate versus total pressure ratio, for a range of corrected speed lines. Key engine operating points along the vehicle trajectory are superimposed onto the fan map. Corrected speed lines are expressed as a percent of the design rotational speed. 


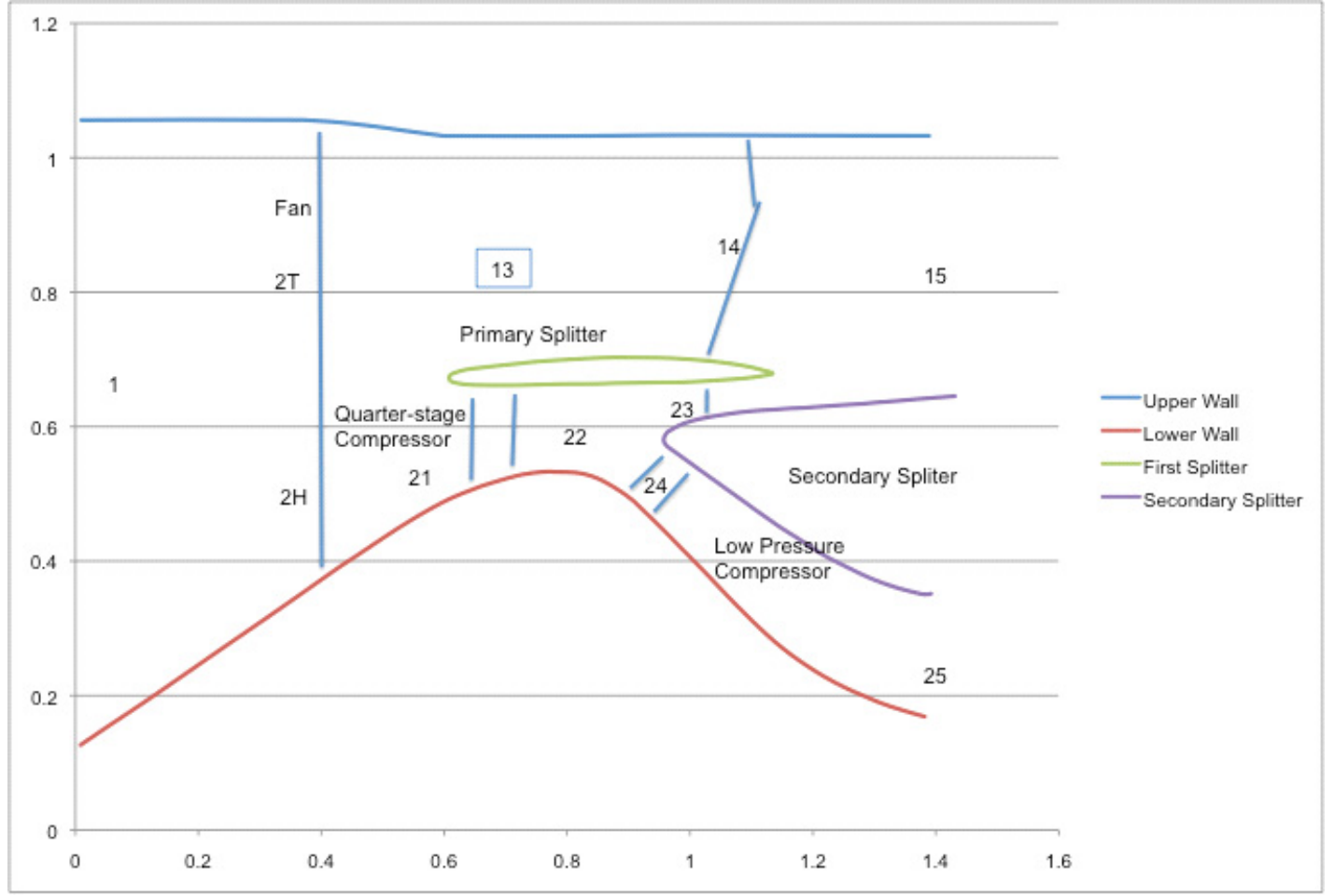

Figure 7.-Engine region analyzed with NPSS and GlennICE.

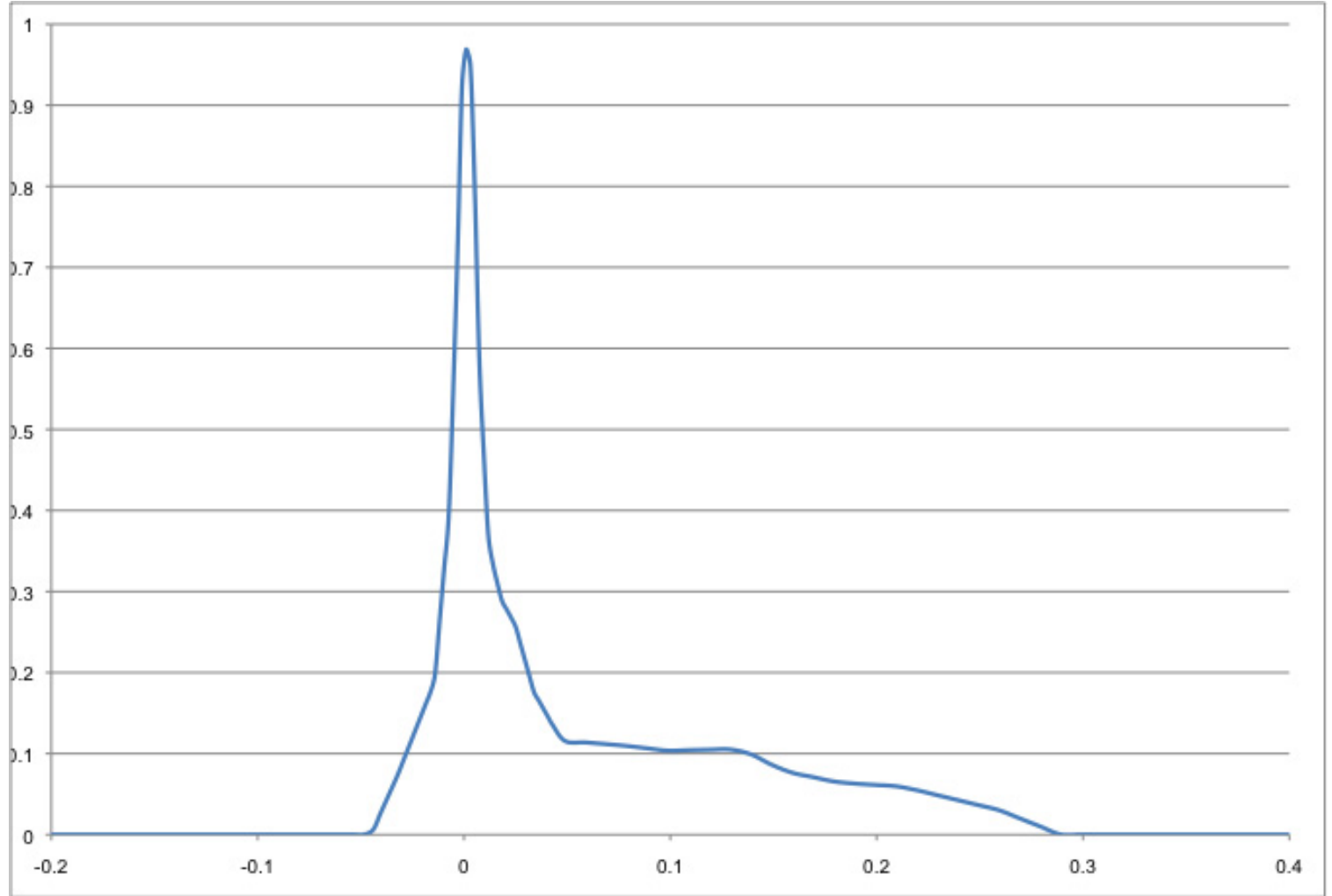

Figure 8.-Collection efficiency for $\mathrm{E}^{3}$ test case. 


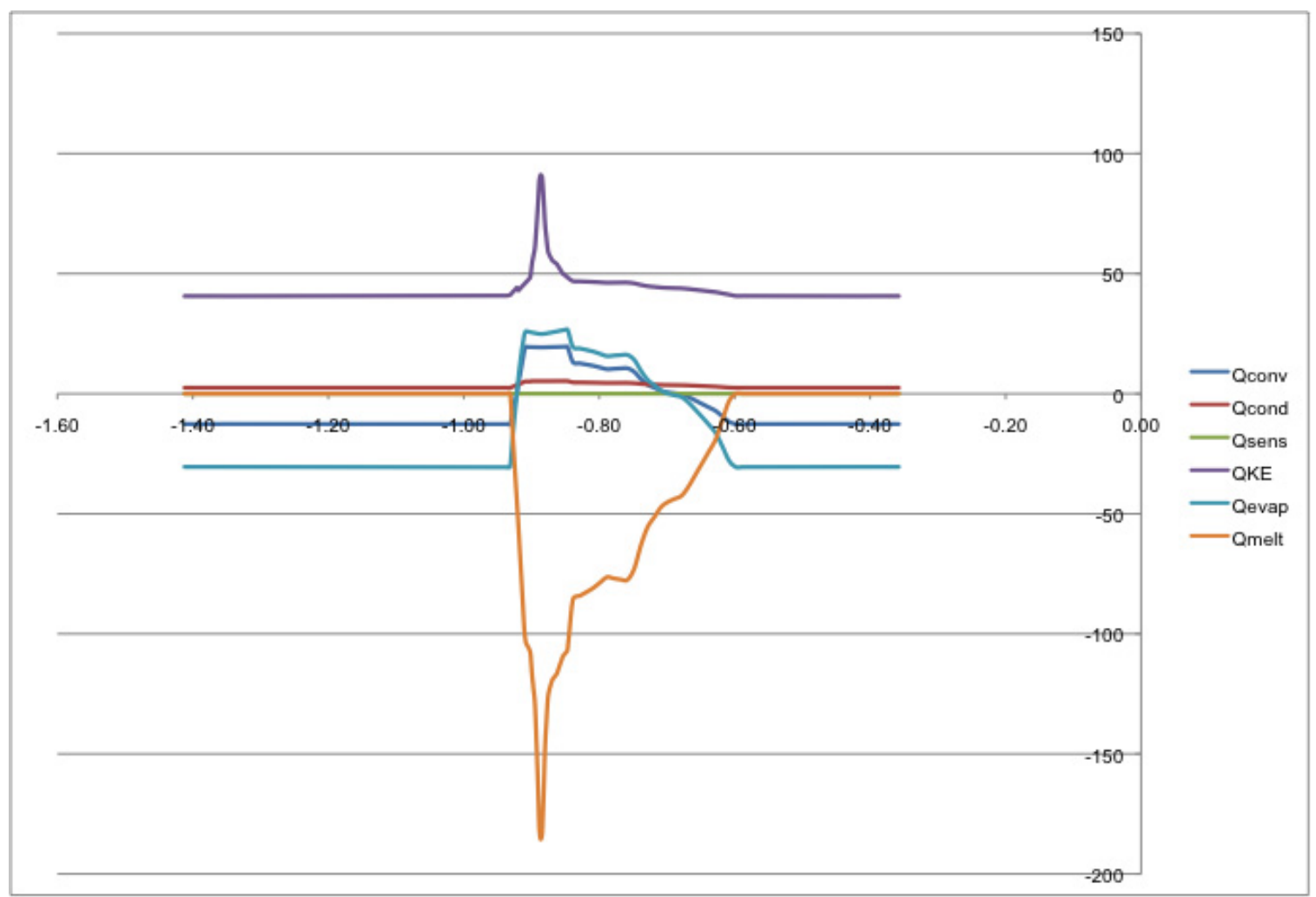

Figure 9.-Energy balance terms for $\mathrm{E}^{3}$ test case.

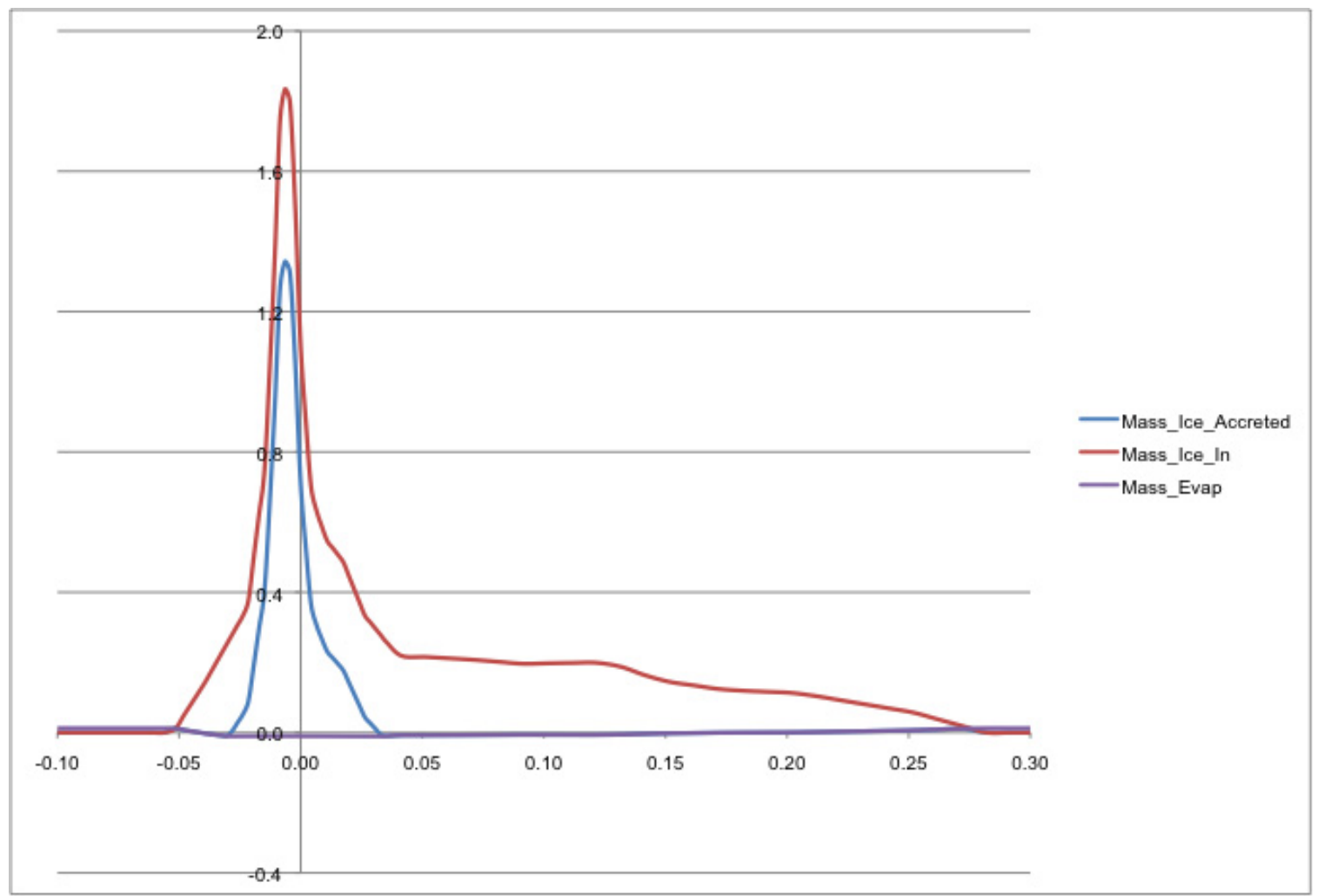

Figure 10.-Mass balance terms for $\mathrm{E}^{3}$ test case. 


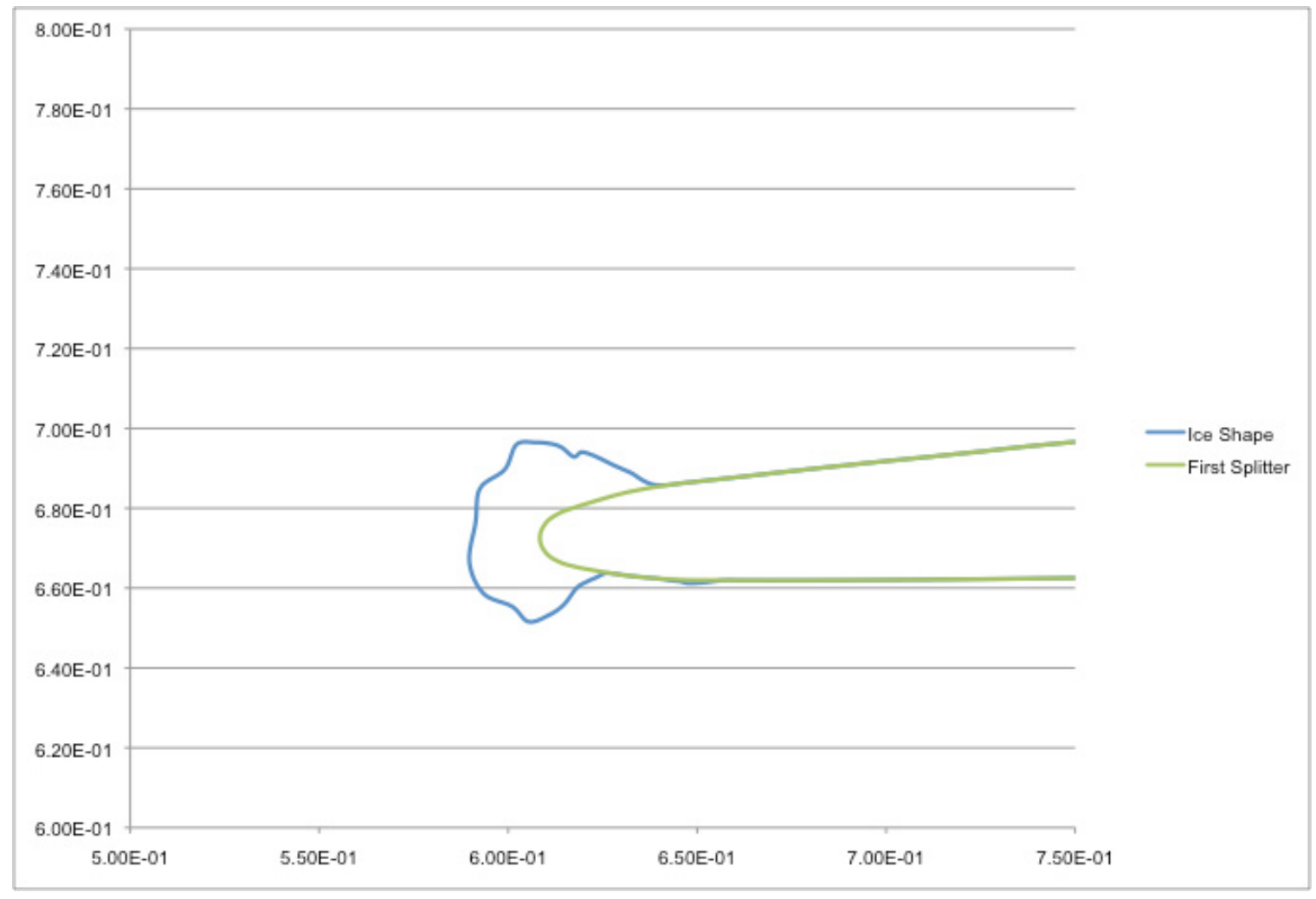

Figure 11.-Ice shape for $E^{3}$ test case. 


\begin{tabular}{|c|c|c|}
\hline \multicolumn{2}{|c|}{ REPORT DOCUMENTATION PAGE } & $\begin{array}{l}\text { Form Approved } \\
\text { OMB No. 0704-0188 }\end{array}$ \\
\hline \multicolumn{3}{|c|}{ 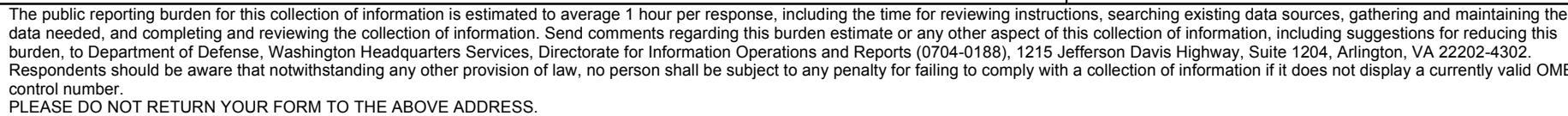 } \\
\hline $\begin{array}{l}\text { 1. REPORT DATE (DD-MM-YYYY) } \\
01-02-2011\end{array}$ & $\begin{array}{l}\text { 2. REPORT TYPE } \\
\text { Technical Memorandum }\end{array}$ & 3. DATES COVERED (From - To) \\
\hline \multirow{3}{*}{\multicolumn{2}{|c|}{$\begin{array}{l}\text { 4. TITLE AND SUBTITLE } \\
\text { Mixed Phase Modeling in GlennICE With Application to Engine Ici }\end{array}$}} & 5a. CONTRACT NUMBER \\
\hline & & 5b. GRANT NUMBER \\
\hline & & 5c. PROGRAM ELEMENT NUMBER \\
\hline \multirow{3}{*}{\multicolumn{2}{|c|}{$\begin{array}{l}\text { 6. AUTHOR(S) } \\
\text { Wright, William, B.; Jorgenson, Philip, C.E.; Veres, Joseph, P. }\end{array}$}} & 5d. PROJECT NUMBER \\
\hline & & 5e. TASK NUMBER \\
\hline & & $\begin{array}{l}\text { 5f. WORK UNIT NUMBER } \\
\text { WBS 609866.02.07.03.04 }\end{array}$ \\
\hline \multicolumn{2}{|c|}{$\begin{array}{l}\text { 7. PERFORMING ORGANIZATION NAME(S) AND ADDRESS(ES) } \\
\text { National Aeronautics and Space Administration } \\
\text { John H. Glenn Research Center at Lewis Field } \\
\text { Cleveland, Ohio 44135-3191 }\end{array}$} & $\begin{array}{l}\text { 8. PERFORMING ORGANIZATION } \\
\text { REPORT NUMBER } \\
\text { E-17618 }\end{array}$ \\
\hline \multirow{2}{*}{\multicolumn{2}{|c|}{$\begin{array}{l}\text { 9. SPONSORING/MONITORING AGENCY NAME(S) AND ADDRESS(ES) } \\
\text { National Aeronautics and Space Administration } \\
\text { Washington, DC 20546-0001 }\end{array}$}} & $\begin{array}{l}\text { 10. SPONSORING/MONITOR'S } \\
\text { ACRONYM(S) } \\
\text { NASA }\end{array}$ \\
\hline & & $\begin{array}{l}\text { 11. SPONSORING/MONITORING } \\
\text { REPORT NUMBER } \\
\text { NASA/TM-2011-216978 }\end{array}$ \\
\hline \multicolumn{3}{|c|}{$\begin{array}{l}\text { 12. DISTRIBUTION/AVAILABILITY STATEMENT } \\
\text { Unclassified-Unlimited } \\
\text { Subject Category: } 03 \\
\text { Available electronically at http://www.sti.nasa.gov } \\
\text { This publication is available from the NASA Center for AeroSpace Information, 443-757-5802 }\end{array}$} \\
\hline
\end{tabular}

\section{SUPPLEMENTARY NOTES}

\section{ABSTRACT}

A capability for modeling ice crystals and mixed phase icing has been added to GlennICE. Modifications have been made to the particle trajectory algorithm and energy balance to model this behavior. This capability has been added as part of a larger effort to model ice crystal ingestion in aircraft engines. Comparisons have been made to four mixed phase ice accretions performed in the Cox icing tunnel in order to calibrate an ice erosion model. A sample ice ingestion case was performed using the Energy Efficient Engine $\left(E^{3}\right)$ model in order to illustrate current capabilities. Engine performance characteristics were supplied using the Numerical Propulsion System Simulation (NPSS) model for this test case.

\section{SUBJECT TERMS}

Turbojet engines; Aircraft icing

\begin{tabular}{|c|c|c|c|c|c|}
\hline \multicolumn{3}{|c|}{ 16. SECURITY CLASSIFICATION OF: } & \multirow{2}{*}{$\begin{array}{l}\text { 17. LIMITATION OF } \\
\text { ABSTRACT } \\
\text { UU }\end{array}$} & \multirow{2}{*}{$\begin{array}{l}\text { 18. NUMBER } \\
\text { OF } \\
\text { PAGES } \\
25\end{array}$} & \multirow{2}{*}{$\begin{array}{l}\text { 19a. NAME OF RESPONSIBLE PERSON } \\
\text { STI Help Desk (email:help@sti.nasa.gov) } \\
\text { 19b. TELEPHONE NUMBER (include area code) } \\
\text { 443-757-5802 }\end{array}$} \\
\hline $\begin{array}{l}\text { a. REPORT } \\
\text { U }\end{array}$ & $\begin{array}{l}\text { b. ABSTRACT } \\
\text { U }\end{array}$ & $\begin{array}{l}\text { c. THIS } \\
\text { PAGE } \\
\text { U }\end{array}$ & & & \\
\hline
\end{tabular}



